\title{
Combination of surgical excision and custom designed silicon pressure splint therapy for keloids on the helical rim Michael Sand ${ }^{* 1}$, Daniel Sand ${ }^{2}$, Pejman Boorboor ${ }^{3}$, Benno Mann ${ }^{1}$, Peter Altmeyer ${ }^{4}$, Klaus Hoffmann ${ }^{4}$ and Falk G Bechara ${ }^{4}$
}

\begin{abstract}
Address: ${ }^{1}$ Department of General and Visceral Surgery, Augusta Kranken Anstalt, Academic Teaching Hospital of the Ruhr-University Bochum, Germany, ${ }^{2}$ Department of Physiological Science, University of California Los Angeles (UCLA), Los Angeles, California, USA, ${ }^{3}$ Department of Plastic and Reconstructive Surgery, Hannover Medical School, Hannover, Germany and ${ }^{4}$ Department of Dermatology and Allergology, RuhrUniversity Bochum, Germany

Email: Michael Sand* - michael.sand@ruhr-uni-bochum.de; Daniel Sand - ucla_daniel@yahoo.com; Pejman Boorboor - pbmhh@hotmail.com; Benno Mann -mann@augusta-bochum.de; Peter Altmeyer - altmeyer@derma.de; Klaus Hoffmann - khmn@derma.de;

Falk G Bechara - f.bechara@elis-stiftung.de

* Corresponding author
\end{abstract}

Published: 12 March 2007

Head \& Face Medicine 2007, 3:14 doi:10.1186/1746-160X-3-14

This article is available from: http://www.head-face-med.com/content/3/I/I4

(C) 2007 Sand et al; licensee BioMed Central Ltd.

This is an Open Access article distributed under the terms of the Creative Commons Attribution License (http://creativecommons.org/licenses/by/2.0), which permits unrestricted use, distribution, and reproduction in any medium, provided the original work is properly cited.
Received: 28 December 2006

Accepted: 12 March 2007

\begin{abstract}
Keloids are defined as dermal fibrotic lesions which are considered an aberration of the wound healing process. Their etiology and pathogenesis are poorly understood. Different treatment modalities are described in the literature depending on the morphology and size of the keloid. We report a case of a large ear keloid on the helical rim which was successfully treated with surgery and a custom designed silicon pressure clip.
\end{abstract}

\section{Background}

Keloids are defined as dermal fibrotic lesions which are considered an aberration of the wound healing process. They are included in the spectrum of fibroproliferative disorders and can potentially occur anywhere on the body. Areas more commonly affected are the anterior chest, shoulders, flexor surfaces of the extremities, and the ears.

Keloids on the ears present several therapeutic challenges. They are common after small skin excisions and other procedures, including drainage of auricular hematomas, repair of other auricular traumas, or as secondary keloid formation after prior keloid excision.

Several procedures have been described for effective treatment of keloid scars. They include silicon occlusive dressings, mechanical compression, radiation, cryosurgery, topical Imiquimod application, bleomycin tattooing, intralesional injections of steroids, 5-floururacil, as well as interferon-alpha, -beta or -gamma in combination with excisional surgery [1-7]. Although optimal conditions for the prevention of keloid formation are still unknown the combination of exicisional surgery and the placement of a silicone gel sheet over the wound surface with the application of light pressure are known to be advantageous [8$10]$.

In the following case report we describe a custom designed silicon pressure splint which was successfully used for preventive, postoperative treatment of a large keloid formation on the helical rim.

\section{Case}

A 25-year-old Caucasian female with skin type 2 (Fitzpatrick classification) presented because of a plum-sized 
pedunculated keloid on the upper part of her left helical rim. She reported that 10 years ago she had already experienced formation of a nodule in this area which became evident 6 months after an ear piercing. This keloid-like nodule was excised twice and injected with steroids. At the time of presentation the plum-sized keloid on her helical rim had been increasing in size and was accompanied by severe pruritus (Fig 1). We introduced our patient to an audiology technician in order to design and build a specially silicon pressure splint for her left ear (Fig 2).

The keloid was then excised with cold steel. Immediately after the operation a combination of $0.5 \mathrm{ml}$ triamcinolonacetonid and scandicain $2 \%$ was intralesionally injected. The custom made silicon splint was applied directly after surgery and steroid injection (Fig 3). The injections were repeated at intervals of 8 weeks for 12 months. The patient was instructed to wear the splint for $24 \mathrm{~h}$ a day, 7 days a week. A clinical check-up one year and 24 months after the last injection showed no tendency to relapse (Fig 4 and Fig 5).

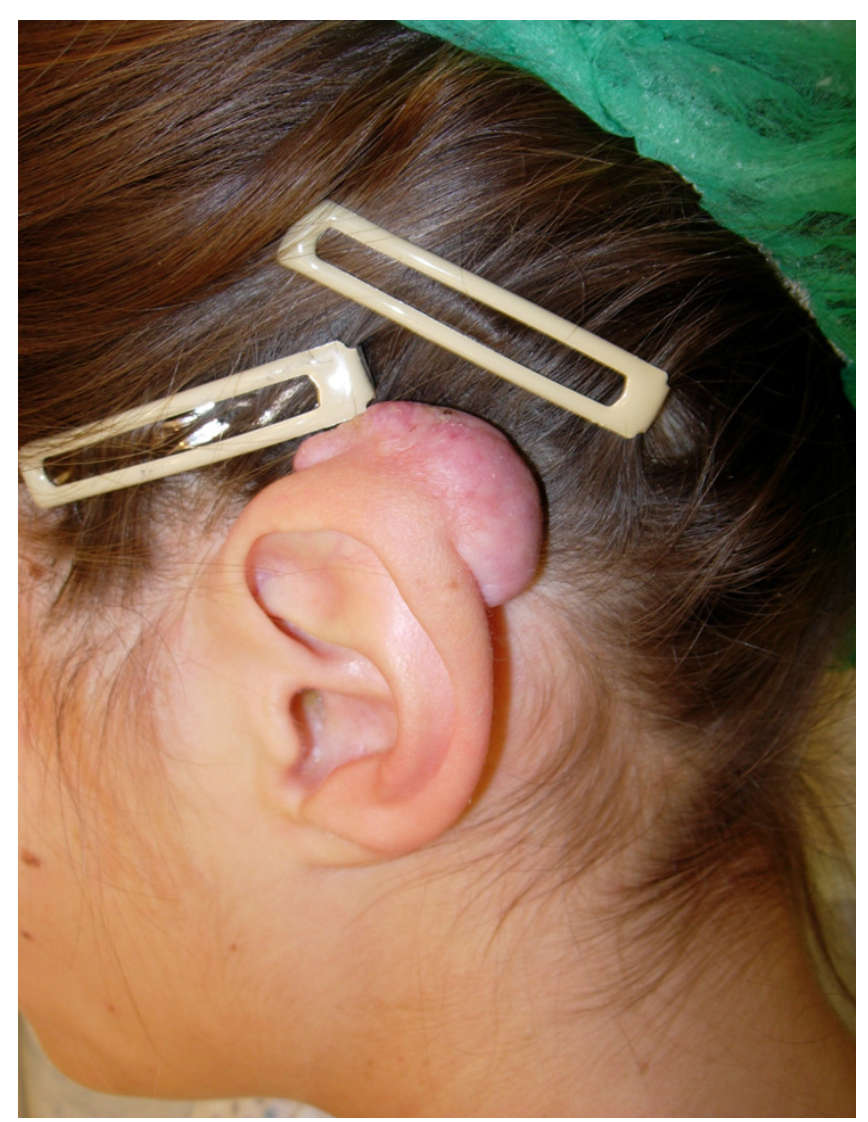

\section{Figure I}

Plum-sized keloid on the left helical rim.

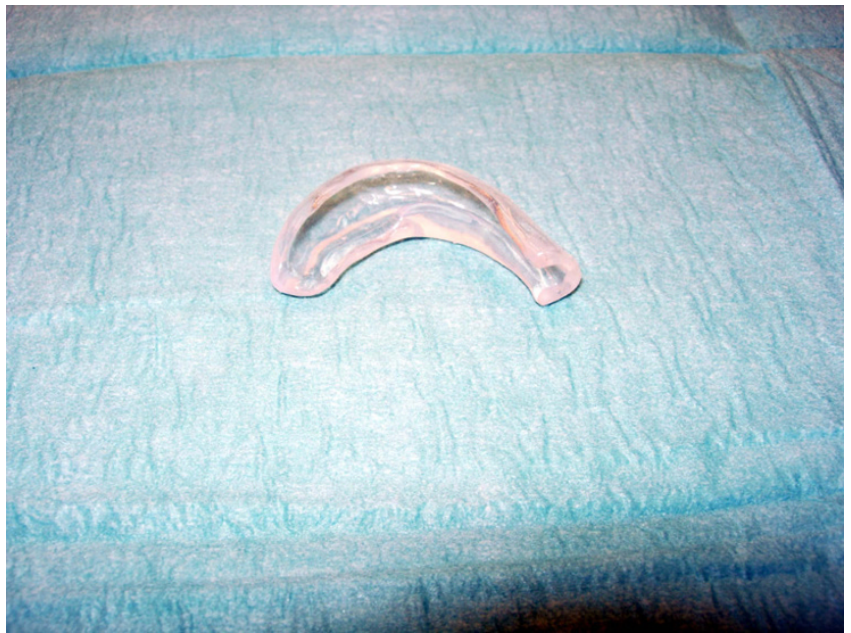

\section{Figure 2}

Custom-build silicon pressure splint for the left helical rim.

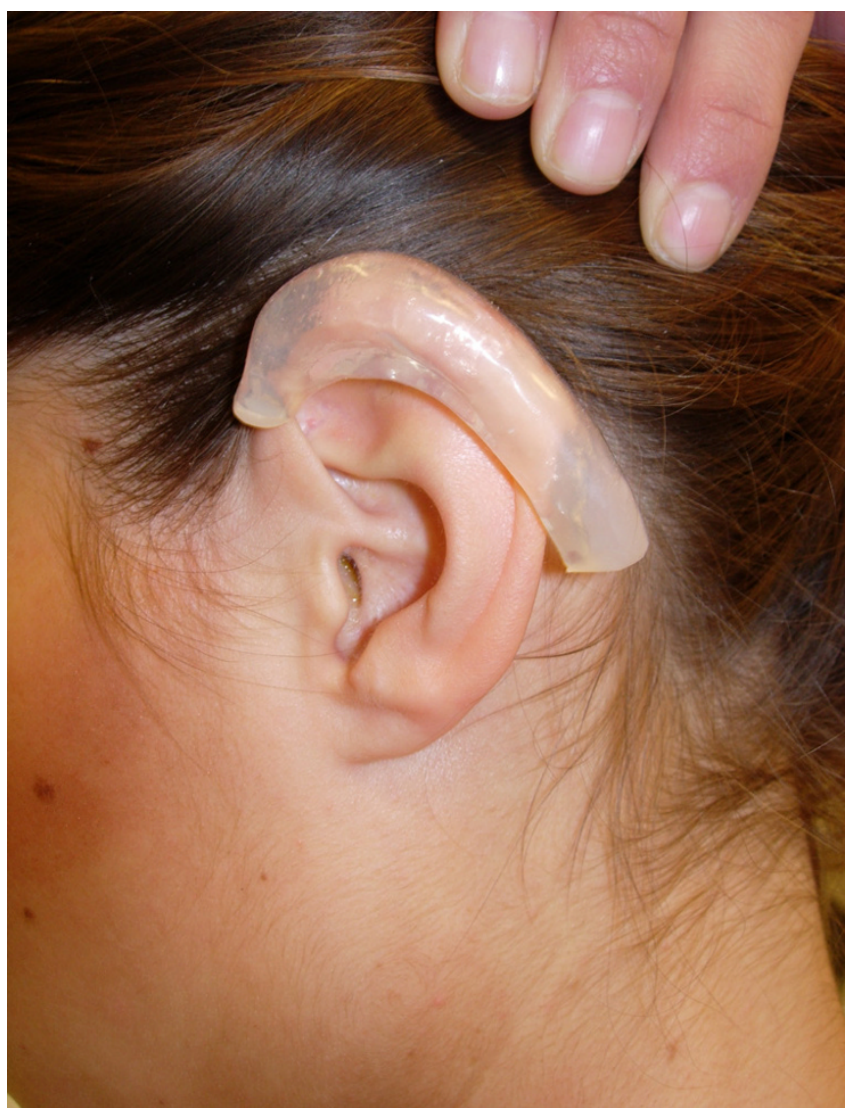

Figure 3

Patients' left ear after keloid excision with silicon pressure splint on the left helical rim. 


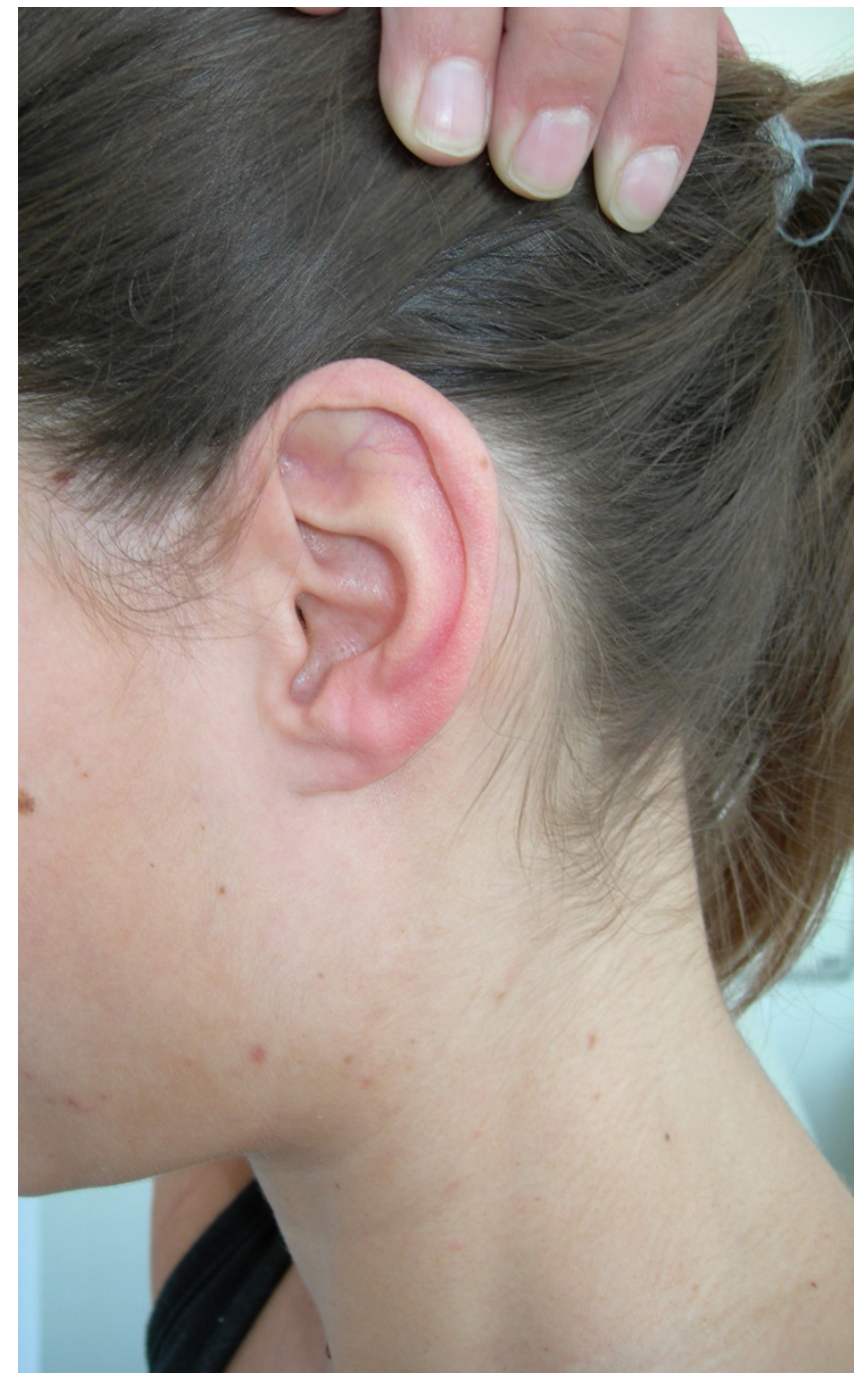

Figure 4

Lateral view on the patients left ear 24 months after the last injection.

\section{Discussion}

Although the incidence of keloid formation is predominantly in darkly pigmented individuals, who form keloids up to 19 times more than Caucasians, those Caucasians who do are among skin types I and II and, as in our patient, are the most difficult ones to treat [11]. After an earring piercing, our patient experienced the third relapse of a keloid on the helical rim which had been unsuccessfully treated with excision and intralesional steroid-injection before.

After surgery, the combination of several preventive steps is essential for a successful treatment plan. It is known that surgical monotherapy results in a high incidence of recur-

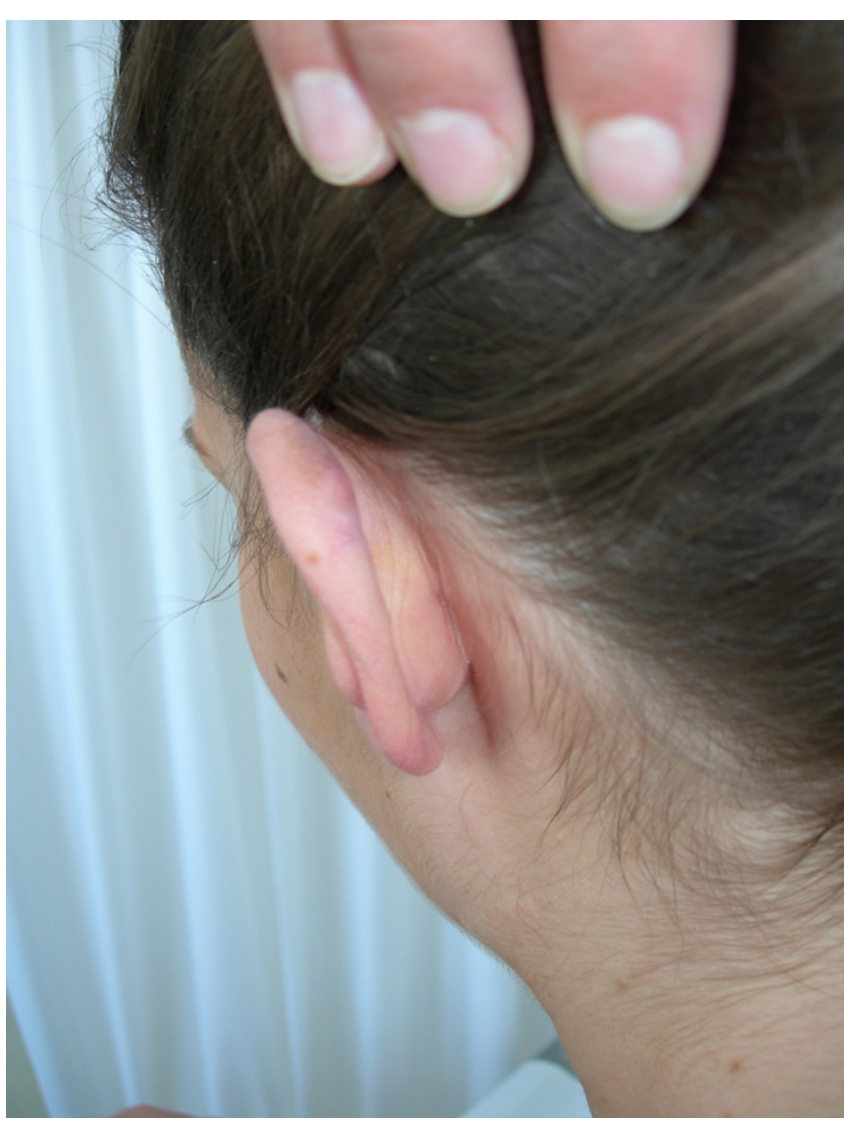

Figure 5

Posterior view on the patients left ear 24 months after the last injection.

rence $(50-100 \%)[12,13]$. Additionally surgical excision and primary closure should be performed with as little wound tension as possible which is not always an easy task where the amount of skin is limited, as on the anterior side of the ear. Hence, we utilized multi-modal standard therapy forms in this patient.

Surgical excision and postoperative intralesional injection of steroid was combined with silicon gel sheeting and compression therapy with an individually designed silicon pressure splint for the helical rim. The procedure combines the advantageous effects of pressure and silicon gel sheeting. Silicon has been described as effective in preventing the development of keloids. It reduces keloid scar formation by $70 \%$ when used consistently [14]. There are several theories of the action mechanism. Although some authors propose that silicon diffuses from the surface of the silicon gel sheets and reduces keloid ground substance it is more likely that retardation of epidermal water loss and a subsequent increase of wound hydration is responsible for the keloid-inhibiting $[15,16]$. 
Compression therapy with dressings or devices that apply more than $24 \mathrm{mmHg}$, the capillary pressure, create a hypoxic microenvironment which results in fibroblast, and, subsequently, collagen degradation. Pressure earrings with compression plates which are available in different sizes are successfully used for ear lobe keloids. It is obvious that the helical rim with its concave anterior and convex posterior surface is not easily amenable for compression. The silicon pressure splint introduced here not only enjoys all the advantages of silicon dressings but also successfully delivers pressure on the helical rim.

We suggest that in cases of keloids on the helical rim the above described custom designed silicon pressure splint combined with subsequent steroid injections respects the delicate anatomy of the helical rim and can be a therapeutic approach with strong benefit for the patient.

\section{Authors' contributions}

MS: Surgeon who performed the operation, documented and prepared the draft

DS: Literature search, revision of bibliography and helped with editing of the manuscript

PB: Helped in preparing the draft

BM: Edited most of the manuscript

PA: Revised and edited the manuscript and helped in preparing the draft

$\mathrm{KH}$ : Literature search and edited part of the manuscript

FGB: Surgeon who performed the operation and edited part of the manuscript and helped in preparing the draft

\section{Acknowledgements}

The written consent was obtained from the patient.

\section{References}

I. Kauh YC, Rouda S, Mondragon G, Tokarek R, diLeonardo M, Tuan RS, Tan EM: Major suppression of pro-alpha I(I) type I collagen gene expression in the dermis after keloid excision and immediate intrawound injection of triamcinolone acetonide. J Am Acad Dermatol 1997, 37(4):586-9.

2. Ogawa R, Mitsuhashi K, Hyakusoku H, Miyashita T: Postoperative electron-beam irradiation therapy for keloids and hypertrophic scars: retrospective study of 147 cases followed for more than 18 months. Plast Reconstr Surg 2003, I I I(2):547-53.

3. Naeini FF, Najafian J, Ahmadpour K: Bleomycin tattooing as a promising therapeutic modality in large keloids and hypertrophic scars. Dermatol Surg 2006, 32(8): I023-9.

4. Maarouf M, Schleicher U, Schmachtenberg A, Ammon J: Radiotherapy in the management of keloids. Clinical experience with electron beam irradiation and comparison with $X$-ray therapy. Strahlenther Onkol 2002, I 78(6):330-5.

5. Rusciani L, Rossi G, Bono R: Use of cryotherapy in the treatment of keloids. J Dermatol Surg Oncol 1993, I9(6):529-34.
6. Berman B, Kaufman J: Pilot study of the effect of postoperative imiquimod $5 \%$ cream on the recurrence rate of excised keloids. J Am Acad Dermatol 2002, 47(4):209-I I.

7. Berman $B$, Villa $A$ : Imiquimod $5 \%$ cream for keloid management. Dermatol Surg 2003, 29(I 0): I050-I.

8. Ahn ST, Monafo WW, Mustoe TA: Topical silicone gel: A new treatment for hypertrophic scars. Surgery 1989, 106:781-6.

9. Sproat JE, Dalcin A, Weitauer N, Roberts RS: Hypertrophic sternal scars: Silicone gel sheet versus Kenalog injection treatment. Plast Reconstr Surg 1992, 90:988-92.

10. Fulton JE Jr: Silicone gel sheeting for the prevention and management of evolving hypertrophic and keloid scars. Dermatol Surg 1995, 2 1:947-51.

II. Alhady SM, Sivanantharajah K: Keloids in various races. A review of 175 cases. Plast Reconstr Surg 1969, 44(6):564-6.

12. Darzi MA, Chowdri NA, Kaul SK, Khan M: Evaluation of various methods of treating keloids and hypertrophic scars: a 10 year follow-up study. Br J Plast Surg 1992, 45(5):374-9.

13. Lawrence WT: In search of the optimal treatment of keloids: report of a series and a review of the literature. Ann Plast Surg 1991, 27(2): 164-78.

14. Fulton JE: Silicone gel sheeting for the prevention and management of evolving hypertrophic and keloid scars. Dermatol Surg 1995, 2 I ( I I):947-5I.

15. Ahn ST, Monafo WW, Mustoe TA: Topical silicone gel for the prevention and treatment of hypertrophic scar. Arch Surg 1991, I 26(4):499-504.

16. de Oliveira GV, Nunes TA, Magna LA, Cintra ML, Kitten GT, ZarpelIon S, Raposo Do Amaral CM: Silicone versus nonsilicone gel dressings: a controlled trial. Dermatol Surg 200I, 27(8):72I-6.

Publish with Biomed Central and every scientist can read your work free of charge

"BioMed Central will be the most significant development for disseminating the results of biomedical research in our lifetime. "

Sir Paul Nurse, Cancer Research UK

Your research papers will be:

- available free of charge to the entire biomedical community

- peer reviewed and published immediately upon acceptance

- cited in PubMed and archived on PubMed Central

- yours - you keep the copyright 